\title{
NARRATIVES D'EMIGRACIÓ. Històries de vida de dos joves catalans emigrats a Londres
}

\author{
Clara RUBIO ROS \\ Universitat Autonoma de Barcelona \\ clara.ruro@gmail.com, clara.rubio@uab.cat
}

\section{EMIGRATION NARRATIVES: Life stories of two young Catalan migrants in London}

Resumen: Les històries de vida són un mètode de recerca relativament nou en ciències socials però que és de gran interès per la profunditat de coneixement que aporten. Aquest article ofereix dues històries de vida de dos joves catalans emigrats a Londres en el context de l'actual crisi econòmica, la Blanca i el Lluís, on es mostren les seves motivacions per marxar, les experiències que tenen a la capital britànica $\mathrm{i}$ com és el seu retorn a Catalunya. Els relats tenen per objectiu narrar de quina manera aquests joves han viscut l'experiència migratòria a partir dels materials recollits en el treball de camp amb la intenció d'aportar algunes claus sobre el perquè del fenomen migratori juvenil així com també debatre les aportacions del mètode d'històries de vida en ciències socials.

Abstract: Life stories are a relatively new research method in social sciences but they are also of great interest due to the deep knowledge they bring. This article offers two life histories of two Catalan young migrants in London, Blanca and Luis, that have left Catalonia during the current economic crisis. The text shows their motivations to leave, the experiences they have had in the British capital and how was their return to Catalonia. The stories are intended to describe is the migration process using materials collected in the fieldwork, aiming to provide some clues about why the Catalan youth migration occurs, as well as discussing the contributions of the method of life histories to the social sciences.

Palabras clave: Història de Vida. Emigració. Joventut. Londres. Catalunya

Life History. Emigration. Youth. London, Catalonia 


\section{Introducció}

Els processos migratoris, en tant que fets socials, poden ser similars en la forma, tot $\mathrm{i}$ que sovint són viscuts de manera molt diferent pels seus protagonistes. D’aquesta manera, encara que els científics socials delimitin fluxos migratoris, tipologies de persones migrades o estudiïn com és la seva integració a les societats d'acollida, entremig de totes aquestes generalitzacions hi ha persones concretes amb històries singulars. El present article pretén mostrar algunes d'aquestes particularitats a través de dos exemples d'història de vida de persones que han emigrat. Es tracta del cas de l'emigració juvenil catalana a Londres en un context de crisi econòmica, un fenomen que en els darrers anys ha assolit una gran importància a nivell social i polític i que he estudiat en el marc d'una tesi doctoral basada en el treball de camp fet a Londres i a Catalunya entre els anys 2013 i 2016.

Durant el treball de camp vaig fer quatre històries de vida a quatre joves catalans a Londres que responien a perfils diferents: motivacions per marxar a Londres, gènere i estratègia. De les quatre històries de vida realitzades, aquí se'n presenten dues, la del Lluís i la de la Blanca, les quals han estat escollides per mostrar experiències basades en expectatives molt diferents, estratègies diverses per emigrar a Londres i també tancaments de l'estada que responen a motius que difereixen entre sí. La mostra d'aquestes històries de vida pretén aportar algunes claus de comprensió del fenomen global ja que, com Cabré i Domingo (2013) defensen, l'emigració juvenil catalana i espanyola és un fenomen més important en la seva dimensió qualitativa, allò que significa i implica, que no pas en la seva dimensió quantitativa.

\section{Metodologia}

\section{Les històries de vida com a mètode}

Les històries de vida es comencen a estendre com a metodologia de recerca a partir de la segona meitat del segle $\mathrm{XX}$, moment en què científics socials comencen a proposar mètodes qualitatius com a alternativa al positivisme, que començava a estar en crisi. A partir d'obres com La imaginación Sociológica de C. Wright Mills escrita al 1959 es comença a proposar el mètode biogràfic com a mètode d'investigació a partir del qual poder "llegir una història social" (Feixa 2006: 2). Com ja Pujadas defensa al seu llibre (2002), és a través d'aquestes històries de vida, en tant que biografies individuals, que podem accedir a un coneixement social profund i familiaritzar-nos amb els sistemes socioculturals. Un dels antecedents dels relats biogràfics emprats en la sociologia és The Polish Peasant in Europe and America, de Thomas i Znaniecki (1918-20), el qual en la seva introducció metodològica diu que el mètode biogràfic amb el que treballa aporta "el tipus de dades més perfecte amb les que els sociòlegs poden esperar treballar".

Els avantatges del mètode biogràfic en ciències socials són varis, tot i que el més rellevant és la profunditat del coneixement al que es té accés. No obstant, el mètode no ha estat exempt de crítiques i preocupacions metodològiques per part de la comunitat acadèmica, fins i tot dins els mateixos defensors del mètode. Una de les crítiques va ser apuntada per Kluckhohn (1945), i fa referència al perill de superficialitat en les histories de vida. És a dir, que l'investigador es perdi en la narrativa de la història de vida i no arribi a fer una anàlisi en profunditat a nivell socio-cultural; preocupació que també comparteixen Ferrarotti (1981) i Pujadas (2002). Per pal-liar aquest repte, l'historiador Niethammer (1989) proposa fer servir el concepte d'habitus de Bourdieu amb l'objectiu de fer el pont entre la perspectiva individual i el sistema socio-cultural, i així fer una connexió entre "la subjectivitat expressiva de la consciència i l'objectivitat construïda de les estructures" (Niethammer 1989: 15). Pujadas (2002) afegeix altres les limitacions i/o desavantatges metodològiques que poden tenir les històries de vida si no es duen a terme d'una manera rigorosa, entre les que senyala: la difi- 
cultat de trobar informants disposats a col-laborar, la no validació de la informació obtinguda a partir d'entrevistes a terceres persones o material complementari, que no se sàpiga com fer el tractament i l'anàlisi de la informació, o el fet de pensar que el relat parla per si mateix, sense analitzar-lo en profunditat. Per pal-liar les limitacions, les històries de vida que aquí es presenten estan basades en les dades recollides durant una estada de treball de camp de llarga durada (del 2013 al 2016) tant a Londres com a Barcelona, el qual ha permès seguir de manera sistemàtica i regular als informants, tot assolint una relació de confiança amb la que s'ha pogut treballar tots els aspectes que es mostren en les seves històries de vida. És aquesta estada llarga la que ha permès obtenir dades en profunditat dels informants, anant més enllà del propi discurs i indagant sobre les pràctiques, coneixent persones i històries de la seva xarxa social, i assistint i fent observació participant en diferents esdeveniments amb la intenció de recollir dades el màxim de profundes possible.

S'han escollit les històries de vida de la Blanca i d'en Lluís (els noms són pseudònims triats pels propis informants) per ser dues històries similars, ja que narren un procés d'emigració juvenil a Londres, i complementàries alhora, ja que són perfils diferents: per gènere, motivacions, estudis, experiències a Londres i motius de retorn; tot perseguint comprendre dos moments clau de l'emigració dels joves: la construcció d'una "vida" a la capital britànica i la persecució de feines qualificades d'acord amb els estudis obtinguts a Catalunya. Els materials han estat recollits durant el treball de camp dut a terme entre l'octubre de 2013 i el febrer de 2016 (inclou observació participant, entrevistes en profunditat i anàlisis de documents secundaris); tant a la ciutat de Londres, on s'ha recollit informació sobre els motius de l'emigració i les experiències a la ciutat d'acollida; com a Catalunya, on s'ha recollit informació del seu procés de retorn. Els materials que s'han emprat per escriure la narrativa de la Blanca han estat, a més a més de les entrevistes individuals (10 hores d'entrevistes gravades), el bloc online que ha anat redactant durant tot el seu procés migratori, la seva pàgina personal de Facebook i trobades amb amics i familiars a les que he assistit durant el treball de camp, tant a Londres com una vegada retornada a Catalunya. Els materials que he tingut en compte per construir la narrativa d'en Lluís són entrevistes conjuntes amb la seva parella i entrevistes individuals (un total de 9 hores d'entrevistes gravades), la seva pàgina personal de Facebook, el seu bloc professional, treballs periodístics que ha anat desenvolupant i trobades amb amics durant la seva estada a Londres i un cop retornat a Catalunya.

\section{Els perfils dels joves}

La Blanca va néixer a Mollet l'any 1986 i va marxar a Londres amb 27 anys. És membre d'una família nombrosa, diplomada en arquitectura tècnica i actualment està acabant la carrera d'organització industrial. Té experiència en arquitectura tècnica, tot i que en els moments abans de marxar treballava en una botiga d'esports a causa de la manca d'oportunitats laborals qualificades. Durant tota la seva adolescència i joventut va dedicar el seu temps lliure al món del lleure, primer com a monitora d'esplai i posteriorment com a directora de lleure. Va marxar a Londres l'octubre de 2013 amb la intenció de posar-se a prova a ella mateixa i de treballar. Tot i que en un inici no es plantejava treballar en el camp de l'arquitectura i la construcció, després de vuit mesos ho va aconseguir. Al cap d'un any i tres mesos, al desembre de 2014, va decidir tornar a Catalunya i invertir els seus esforços en construir el seu futur allà on volia viure.

El Lluís va néixer a Badalona l'any 1989 i va marxar a Londres amb 22 anys. Té un germà més gran i està llicenciat en periodisme. Abans de marxar a Londres ja tenia experiència en ràdio i premsa com a becari, en pràctiques o amb contractes precaris. Mesos abans de marxar, i ja havent acabat la carrera, treballava sense cobrar en una de les ràdios més importants de Catalunya. Veient les perspectives de futur va decidir, juntament amb la seva 
parella, marxar a Londres amb una beca Leonardo da Vinci ${ }^{1}$, la qual cosa li va permetre tenir feina i allotjament assegurats durant els primers mesos. Van arribar a Londres al gener de 2012 i va anar fent diferents feines que li van permetre compaginar el món laboral amb altres projectes periodístics. Al setembre del 2013 va decidir tornar a Catalunya i apostar per la seva professió al país d'origen.

\section{Històries de vida}

A continuació es mostren les històries de vida de la Blanca i del Lluís, les quals han estat escrites per mi a partir de la informació recollida al treball de camp. El relat, escrit en forma de reflexió de tot el procés migratori, està complementat amb fragments de les entrevistes en profunditat. Val a dir que les dues narracions han estat supervisades i acceptades pels informants.

\section{La Blanca}

A Catalunya estava bé, podríem dir que sí. Tenia una feina fixa com a dependenta a una botiga, l'opció de promocionar-me com a cap de secció, m'havia independitzat a Vic i estava acabant la segona carrera. Podríem dir que ho tenia tot. Però de fet no ho era tot per mi, anava cada dia a la feina preguntant-me què era el que realment volia, em sentia buida.

I tant! Podria haver continuat així fins que acabés la crisi econòmica i després apostar pel que jo vaig estudiar: arquitectura tècnica. En aquell moment, absolutament impossible! Amb la crisi era molt complicat i tampoc tenia clar si volia dedicar-me a un sector del que n'estava una mica escarmentada. Però bé, amb el temps hagués acabat la segona carrera, organització industrial, i el meu currículum encara hagués estat més fort i potser, amb sort, hagués acabat trobant una bona feina. Però dins meu hi havia una Blanca revoltada amb l'educació que havia rebut i no estava segura de voler-me dedicar al sector.

Per altra banda, havia dedicat la meva vida al món de l'esplai i se'm donava bé, m'apassionava i creia que l'educació hauria d'anar molt diferent de com està anant a la nostra societat, hauria de ser més propera al món del lleure. Una cosa i l'altra em va dur a una crisi bastant profunda, no econòmica, sinó personal: estava farta de la situació estable en la que estava, la qual em portava al no-res, a un futur insípid i que no era per mi. Necessitava canvis. Necessitava trobar-me. Necessitava fer-me forta i apostar pel meu futur.

Permi [Londres] és un entremig entre tota la formació que he fet i la vida estable que en teoria ha de venir, no? És un entremig d'experiència per experimentar, viure, conèixer [...] Londres serveix per adonar-te de tot el que tens, és el nus de tota aquesta formació que he tingut, és una etapa que vas vivint, que no saps perquè, però que ho has de viure! Una etapa que serveix per lligar tot el que tens i decidir què vols fer després (Blanca, entrevista número 1)

I marxar va ser la manera com vaig decidir fer-me forta. Pensant-ho bé, no calia que hagués marxat a Londres, podria haver fet el mateix anant a fer un voluntariat al Raval, un recés a Montserrat, anant a l'Àfrica a col·laborar amb un projecte de cooperació... perquè ens entenguem, buscava el que la gent va a buscar a l'Índia quan marxen de viatge espiritual: em buscava a mi. Però és clar, Londres és Londres, i només em cridava realment aquesta ciutat, tot el que havia d'aprendre havia de ser allà. A més a més tenia l'oportunitat de millorar l'anglès (que sempre havia estat una assignatura pendent per a mi), de viure en una de les ciutats més cosmopolites i amb més oferta sòcio-cultural del món, de trobar feina

1 Les beques Leonardo da Vinci són un programa de la Unió Europea que ofereix beques laborals de 2 -39 setmanes als ciutadans dels estats membre. 
relativament fàcil (o això creia) i tot això a només dues hores de vol de Barcelona i amb bitllets d'avió low-cost d'uns cent euros anada i tornada. Res no m'impedia provar-ho. I així ho vaig fer: vaig comprar un bitllet d'anada a Londres i vaig reservar tres nits a un hostal del centre de la ciutat.

Havia llegit a fòrums que deien que era molt millor agafar un hostal els primers dies $\mathrm{i}$ després buscar allotjament des d'allà, que era gairebé impossible trobar alguna cosa decent i fiable sense estar a la ciutat. Creia que tres nits eren més que de sobres, però finalment no va ser suficient i en vaig haver d'estar-m'hi 10 fins que no em vaig poder mudar a la nova casa. La recerca d'allotjament a Londres és una de les bogeries més grans que he vist mai, pots arribar a veure vuit habitacions per dia, de les quals només la meitat són habitables, i quan finalment en veus una que és decent has de dir que la vols al mateix moment, abans que arribi el següent i te l'agafi. No tens temps a pensar, només a actuar, i ràpid! Vaig anar a veure alguns pisos fins que finalment me'n vaig quedar un a Hammersmith. Es tractava d'una habitació que havia de compartir amb dues altres noies, no era ideal però amb el meu pressupost màxim de 500 lliures al mes era la única cosa que em podia permetre si volia viure en aquella zona. Pagava 80 lliures a la setmana i al pis érem tot noies: una peruana, dues italianes, una taiwanesa, una francesa i jo. 6 noies i un sol lavabo, ja us podeu imaginar! Però de fet tot va anar força bé. Entre nosaltres parlàvem anglès, no era el millor entorn per aprendre el British English perquè totes teníem un accent molt fort, però com a mínim apreníem anglès. En aquest pis hi vaig viure força temps, de fet la durant la gran majoria de la meva estada a Londres.

Així doncs, el primer gran repte estava superat: tenia lloc on dormir a partir de la desena nit. Ara era moment de fer números, de veure amb quins estalvis comptava i fins quan em podia permetre viure a Londres sense feina: dos mesos. D'acord, després de l'aventura de trobar pis tenia 50 dies per trobar feina abans de caure en la bancarrota. Fàcil, relativament. És fàcil trobar feina a Londres si, primer, no tens cap preferència de feina i estàs disposat a fer feines no qualificades; segon, si estàs disposat a acceptar situacions d'incertesa màxima i fins i tot d'explotació. Així va ser la meva primera feina: no qualificada, totalment inestable i amb un gran nivell d'explotació. Vaig trobar feina de cambrera d'esdeveniments. Em cridaven quan necessitaven a gent, tant podia ser un dia a la setmana, quatre, com cap; els contractes de zero hores, que en diuen. I no només això, sinó que era el treballador que cada setmana s'havia de connectar a l'horari online i sol-licitar la feina; llavors els mànagers eren els que acceptaven, o no, els treballadors. Els contractes 0 hores són perfectes pels empresaris i horribles pels treballadors ja que has d'estar sempre disponible perquè mai se sap quan pot sortir feina $i$, per conseqüent, quan podràs comptar amb les sis lliures i poc que et paguen la hora, el salari mínim.

Va ser una experiència dura i alhora xocant, però que també em va ensenyar moltes coses. La primera: allà no ets ningú. D'acord, sí, continues sent la mateixa persona que abans, potser fins i tot una persona amb menys escrúpols, la qual cosa t'hauria de fer més fàcil trobar feina perquè acceptaries moltes coses que abans no haguessis imaginat; però ningú et coneix, ningú et valora i no ets ningú. Això, vulguis o no, és una gran lliçó de vida: marxes perquè et vols menjar el món i només acabes menjant merda, amb perdó. Tens al cap allò que has vist en tantes pel·lícules de Hollywood, "el somni americà": aquells que s'esforcen i treballen dur, independentment de qui siguin i d'on vinguin, acaben aconseguint els seus somnis. I així ens trobem tots els joves emigrats a Londres, desitjant que aquesta història que hem mamat des de sempre també sigui la nostra.

La segona cosa que aprens en llocs així és que tu ets l'últim mono només per la teva condició d'immigrant, estigma que et fa estar molt més lluny del que tu consideres que et mereixes. En el context de la feina de càterings érem molta gent de molts llocs diferents treballant esporàdicament $\mathrm{i}$ intentant fer un salari digne a final de mes a partir de sumar hores 
aquí i allà. Un dia vaig tenir una cap que era de procedència africana, potser de Nigèria, i va ser aquell dia concret que vaig sentir l'etiqueta d'immigrant damunt meu. Aquesta etiqueta anava acompanyada d'una desconsideració i un mal tracte cap a mi només pel fet de ser nova a la ciutat, i això em va fer mal. Crec que va ser aquell dia quan vaig sentir allò que nosaltres devem fer sentir a Catalunya als immigrants. I això em va xocar molt, sentir una etiqueta associada a mi només per la meva condició d'immigrant, sense que ningú em veiés més enllà d'això. A Catalunya tenia amics immigrants però no va ser fins aquest moment que vaig ser conscient de les dificultats que havien hagut de passar en tant que persones que comencen des de zero a un lloc que no és el seu.

I és clar, amb la feina de càterings no en tenia prou. Era tot tan inestable que havia de comptar amb alguna cosa més per assegurar-me les garrofes. Així que vaig continuar buscant. Vaig continuar empaperant la zona on vivia de currículums, acompanyats d'una carta de presentació i d'una carta de recomanació, no fos cas que no em truquessin perquè els faltés informació! Però no ho vaig aconseguir. Finalment em van oferir feina de nanny, i vaig estar contenta perquè em podia dedicar als nens i això m'apassionava! No obstant, en un principi prometia molt i només van acabar sent dos babysittings ${ }^{2}$ al mes, encara més inestable que els càterings, amb la qual cosa vaig haver de buscar més nens per cuidar. Va arribar el Nadal del 2013, tres mesos després de la meva arribada, tenia tres feines i no arribava a treballar cinc dies seguits, amb la qual cosa no tenia prou diners per sobreviure i em trobava buscant els productes més econòmics al supermercat per poder arribar a final de mes. Productes de Sainsbury's basics, que tenen pa de motlle per 50 cèntims de lliura, o iogurts de $500 \mathrm{ml}$ per 45 cèntims. I aquest era el meu viure quotidià, fent comptes cada cop que havia d'obrir el moneder perquè evidentment em venia de pagar quatre lliures pel metro, quatre lliures eren el menjar de tres dies!

Aquell Nadal havia dit a la meva família que el passaria a Londres, havia de treballar i no sabia quan sortiria la feina, per tant vaig optar per quedar-me i esperar si podria cobrir les despeses d'aquelles vacances. Però va arribar el dia 22 i vaig adonar-me que podia passar-me totes les vacances tancada a casa sense que ni em truquessin per treballar, així que vaig decidir agafar un bitllet d'avió a última hora i baixar per sorpresa a casa. Va ser la decisió més encertada que hagués pogut fer, tothom va estar molt content de veure'm i jo molt feliç de ser-hi. I va ser just en aquest viatge que em vaig adonar d'una cosa molt important: que ho estava aconseguint. Havia passat de tenir 3 nits d'hostal pagades a la vora de Hyde Park a tenir un allotjament i feina a Londres. I la sensació de poder veure a distància el que havia aconseguit en aquell temps em va fer sentir orgullosa de mi mateixa i em va ajudar a continuar. I és que és clar, quan estàs a Catalunya tothom t'explica com de bo n'és marxar a fora, com de bé t'ho passes i com d'enriquidora és l'experiència. Però l'experiència de marxar d'Erasmus o per fer un curs d'anglès no té res a veure amb l'experiència dels que anem sense res. Quan vaig marxar no sabia a què m'afrontava, però el fet de tornar a Catalunya i veure-ho amb distància va ser el punt de força que necessitava per continuar.

Al tornar a Londres després de les vacances de Nadal tot va ser molt diferent. Jo mateixa tenia molta més força per continuar lluitant. Vaig prendre la decisió de focalitzar-me en trobar feina de nanny i anar deixant enrere els càterings. Finalment vaig trobar feina 4 dies a la setmana amb una família de dues nenes, cada tarda amb elles. Podia viure més tranquil-lament i aprenia de la vida londinenca familiar i començava a estimar la ciutat. Fins i tot vaig poder fer alguna excursió, conèixer el país on vivia i apuntar-me a un curs de disseny d'interiors molt bàsic a l'escola City Lit. Paral·lelament continuava fent cangurs puntualment amb la primera família. La casualitat va voler que demanés a la mare d'aquesta nena si podia donar-me les revistes de decoració que tenia en una pila vora la finestra. Em

2 Babyssiting és el servei de cangur esporàdic i que depèn de les necessitats familiars. Diferent al servei de nanny, que és regular i amb uns horaris establerts. 
va demanar els motius i els vaig explicar que era arquitecta tècnica i que ara m'havia posat a fer un curs d'interiorisme. Doncs es veu que tenia una empresa de construcció de caves de vins i necessitaven a algú que els dibuixés els plànols, així que em va contractar com a freelance perquè fes feines puntuals. Va ser en aquest moment que em vaig adonar que havia aconseguit el que buscava a Londres: provar-me a mi mateixa que podia arribar on volgués partint de 0 , que podia confiar en mi mateixa i en les meves habilitats. No somniava fer de delineant, però sentia que havia aconseguit posar el peu en aquella ciutat, professionalment parlant. Ara només restava perseverar i treballar fort. Al cap de poc vaig assabentar-me d'una família veïna que buscava una au-pair. Si m'interessava, viuria sense pagar lloguer, cuidant dos germans, cobrant i alhora treballant de freelance. Una mica el que ja feia però amb les condicions molt millorades i amb perspectives reals. Vaig dir que sí.

Desembre de 2014, Londres m'havia aportat aquesta confiança, però sobretot m'havia aportat auto-coneixement. Vaig deixar de ser la Blanca que a tot deia que sí, que només es preocupava pel que els altres necessitaven i que tenia una vida "estable" per passar a ser una Blanca que decidia què volia fer, que es coneixia i no es deixava emportar per les situacions i, sobretot, que triava el seu camí i tenia molt clar on anava. Així doncs, ja havia aconseguit tot el que pretenia, era hora de tornar a Catalunya. I vaig tornar a fer allò que a l'octubre de 2013 havia fet: marxar sense res i construir tot de nou des de 0 . La meva excedència a la botiga havia caducat, no tenia feina, calia veure fins a quin punt els amics que tenia encara ho eren i el futur era incert. Només hi havia una cosa segura: sabia què volia fer i sabia qui era. I així va ser com vaig pensar: si ho he fet a Londres no ho puc fer a Catalunya, la meva terra, el lloc on vull estar? I així vaig tornar. El principi va ser molt dur, no hi havia feina, tirava currículums i no sortia res, però anava fent. Sabia on anava: volia una feina qualificada però sobretot que fos allò que encaixés amb mi, i sabia que ho podia aconseguir. Sis mesos després d'haver arribat, i una mica desanimada amb el retorn a Catalunya, em va sortir una feina d'arquitecta tècnica a Vic com a autònoma, tot el que volia. Vaig poder recuperar el pis on vivia abans i reprendre moltes de les amistats que tenia. A Londres havia après a valorar el meu temps i el contracte d'autònoma era perfecte per poder-me gestionar; a més, a Vic! No he pogut demanar res més. I és que, com tot, cal temps, paciència i treball.

\section{El Lluís}

Tot comença a mitjans del darrer curs de carrera. Fèiem periodisme i les perspectives de futur no eren massa prometedores, no anaven més enllà de pràctiques en algun diari o ràdio, opcions que només estaven obertes per aquells que continuaven matriculats a la universitat, o bé feines no-qualificades en qualsevol bar o cafè del barri. Estàvem en el pitjor any de la crisi econòmica, o això diuen, al 2011, i fins i tot les feines no-qualificades semblaven difícils d'aconseguir. Jo, per exemple, em vaig passar l'estiu treballant a una ràdio nacional catalana després que m'oferissin continuar amb les pràctiques de la universitat durant l'estiu, això sí, amb les mateixes condicions: de franc. Tenia l'opció de fer un màster també, però aquestes coses són molt cares i en periodisme no acaben de donar-te res massa nou ni especial, per tant tampoc era una opció que m'apassionava en aquell moment.

Jo d'això que en diuen "experiència internacional" ja n'havia tingut. Havia anat d'Erasmus a Leuven (Bèlgica), una experiència de la que en tinc molt bons records, fins i tot tants anys després. L'anglès també el portava bé, tenia el nivell Proficiency, un certificat que certament poca gent té a Catalunya; per tant les necessitats de millorar-lo no eren urgents. El que sí que em movia era la meva parella, la Clàudia. Ella també és periodista i també acabava aquell mateix any la carrera, érem de la mateixa promoció. Ella mai va marxar d'Erasmus i tenia l'interès per fer-ho. Davant les poques oportunitats laborals que teníem a Catalunya va començar a preguntar-se si no seria bona idea marxar a l'estranger. No havíem 
viscut mai junts després de gairebé 4 anys sortint, i en teníem ganes. Marxar a l'estranger era una manera de poder-ho fer, i era un motiu més per fer-ho. Aquell mateix darrer any de carrera vam anar a la universitat a fer uns documents a gestió acadèmica, quan ens vam assabentar de manera totalment informal de l'existència d'unes beques anomenades Leonardo da Vinci. No en teníem massa idea, però era un programa de la Unió Europea que t'oferia una feina com a becari a algun país de la Unió i et pagava una quantitat de diners en total, a més del bitllet d'avió d'anada i de tornada. En aquest moment tot va començar a encaixar: la falta d'oportunitats laborals a Catalunya, l'opció d'anar a l'estranger amb alguna beca assegurada, la possibilitat de viure junts... així que ens vam anar a informar a l'oficina internacional de la universitat. Els processos burocràtics els havíem de fer directament des de la universitat, que era la responsable de fer les gestions pertinents. D'entrada hi ha una borsa amb ofertes disponibles però també hi ha l'opció que la persona interessada busqui un lloc on fer les pràctiques, la qual cosa et donava més garanties de que al final et donessin la beca. Com que a Londres no hi havia massa opcions i realment estàvem molt interessants en marxar vam decidir buscar alguna cosa que ens encaixés. Em vaig passar uns quants dies enviant correus electrònics a Londres, l'oferta era bastant atractiva: dos treballadors de franc durant 3 mesos; però no vam tenir massa respostes positives. Finalment, el director d'un museu a Peckham ens va contestar i ens va dir que estaria interessat en l'oferta. Vam formalitzar tots els documents i vam marxar el gener de 2012.

La beca s'acabava al maig del mateix any i havíem de tornar a Barcelona per fer els papers de tancament. No obstant, la intenció des d'un bon inici era quedar-nos fins al setembre del 2012 a Londres per poder treballar als Jocs Olímpics, i així ho vam voler fer. El pla era que durant el temps que durava la beca anàvem buscant feina relacionada amb el periodisme, i que si quan s'anava acostant la data final no havíem aconseguit una feina qualificada, doncs passàvem a buscar qualsevol tipus de feina, només amb l'objectiu de poder sobreviure fins passades les Olimpíades. Va anar passant el temps i no vam trobar cap feina qualificada. A l'abril, doncs, tots dos ens vam posar a enviar currículums en massa. Jo sóc més artesà que no pas la Clàudia, i em mirava amb lupa cadascuna de les candidatures que presentava perquè encaixés perfectament amb el que l'empresa demanava; ella era més industrial i simplement tenia un model general que enviava a tothom, fent-ne adaptacions mínimes. Això feia que mentre la Clàudia n'enviava 30 jo només 5 . A finals del mes de maig ella ja tenia feina a una empresa internacional com a auxiliar d'administració i jo només tenia feina a una cadena de menjar ràpid de Londres. A més a més, a la feina no tenia horaris fixes, sinó que cada setmana sortien els calendaris i ens donaven poques hores de feina a cada treballador; amb la qual cosa ens tenien collats i si mai necessitaven a última hora algú havíem de dir que sí per poder cobrir les hores del contracte. A part de que la feina en sí no m'apassionava, el tema dels horaris em posaven molt nerviós perquè no podia fer cap pla amb els amics, sempre havia d'estar pendent del calendari de la feina.

Les meves grans penes eren tres: la feina en sí, gens gratificant, la pot fer qualsevol; que els horaris te'ls canvien d'un dia per l'altre [...] $i$, per l'altra banda que dius, bé aprofito per aprendre anglès, però és clar, tot són italians, indis, gent de l'est... que parlen igual que tu o pitjor! (Lluís, entrevista número 1)

Aquesta situació, però, va canviar un cop van començar els Jocs. La feina que vaig trobar també va ser a una cadena de cafès i menjar ràpid, però tant els clients com l'empresa eren molt diferents. Per una banda, els clients eren molt més amables. És clar, estaven de festa i anaven a veure un partit que ells havien escollit, no eren treballadors estressats que arribaven tard a la feina! Per altra banda, l'empresa era molt més acollidora, hi havia un ambient molt més distès i també em pagaven una mica més del salari mínim, cosa que s'agraïa. La 
feina estava dins el mateix estadi, amb la qual cosa també vaig tenir oportunitat de veure les olimpíades des de dins, cosa que estava buscant amb molt entusiasme.

Quan la feina de les olimpíades va acabar, la cadena de cafès em va oferir continuar treballant per a ells, vaig acceptar la feina, tot i que aquesta va passar a ser una feina secundària. Vaig aconseguir combinar la feina dels cafès amb una de relacionada amb el periodisme i amb una altra vinculada amb una feina que sempre havia fet: ser mestre. Per una banda, el director del museu on vam fer la beca Leonardo em va donar un mini projecte de recerca de fotografies per una producció audiovisual que estava fent. Es tractava d'una feina d'autònom en la que jo anava fent la recerca de fotografies mentre m'autogestionava el meu propi temps. L'altra feina era de professor de castellà. Mentre vivia a Badalona havia treballat molts anys com a professor de repàs i crec que ho feia força bé perquè els alumnes anaven aprovant les assignatures i no deixaven de venir a les classes! Feia un temps que m'havia apuntat a una agència de classes de castellà $i$ em van oferir un parell de grups. Totes tres feines es podien combinar força bé i em va permetre viure durant la meva estada a Londres. Al redescobrir que el tema de la docència m'agradava vaig aprofitar la meva estada a Londres per treure'm el certificat CELTA, que és un certificat que t'acredita com a professor d'anglès per a persones que no tenen l'anglès com a primera llengua. Aquesta va ser la meva inversió de futur a Catalunya tot estant a Londres. Es tracta del darrer certificat que es pot adquirir dins els certificats de Cambridge School, i creia que el fet de treure-me'l a Londres em donaria punts extres quan tornés a Catalunya. Vaig passar aquell any, doncs, combinant aquestes quatre coses, a més a més d'anar començant petits projectes de periodisme pel meu compte amb gent de Catalunya amb la que mantenia el contacte.

El meu últim objectiu a Londres és, sobretot, no tornar a Catalunya dient que havia estat a Londres estant igual que vaig marxar, no! [...] el que teniem clar quan vam venir és que sortíssim d'aquí amb alguna cosa, un plus per trobar alguna cosa allà. Perquè home, de cambrer, aprendre anglès $i$ ja està (Lluís, entrevista 1).

I un any després d'haver arribat encara érem a Londres, la data de tornada s'havia anat aplaçant. De fet, al gener del 2013 érem molts més joves catalans a Londres que no pas quan vam arribar, al gener del 2012. Amb el temps d'estar allà molta altra gent de la carrera es va interessar per la nostra experiència. Per mala sort durant aquell any la universitat va tancar el programa de les beques Leonardo da Vinci i els nostres companys no vam poder venir amb les mateixes garanties que nosaltres, però això no els va impedir marxar. Ja durant la carrera els nostres propis professors ens dèiem que marxéssim, que Catalunya i Espanya no estava en condicions d'acollir-nos al mercat laboral. Quan vaig fer les pràctiques a la ràdio també m'ho deien, fins i tot em convidaven a marxar perquè també seria un contacte que tindrien a l'exterior. I és que així és el món del periodisme a Catalunya: precari. És per això que un any després de la nostra arribada, al febrer del 2013, érem 10 persones de la meva pròpia classe a Londres. No vull ni imaginar-me quants periodistes catalans i espanyols van arribar marxar durant la crisi si en un moment donat vam arribar a ser 10 persones d'una classe de 60, és a dir el 16'7\% del total, a Londres! I de tots els que en aquell moment érem a Londres només la Clàudia tenia una feina més o menys estable i en condicions;la resta vivíem de contractes precaris i de feines no-qualificades. Però bé, allà estàvem, fent camí poc a poc.

La nostra data de tornada s'anava allargant de sis mesos en sis mesos. Va passar de ser el maig del 2012 (fi de la beca), al setembre de 2012 (fi de les Olimpíades), al maig de 2013 (quan ja feia un any que la Clàudia estava a la feina i, per tant, podia acreditar les competències adquirides), al setembre de 2013 (després de la temporada d'estiu). I aquí és on em vaig quedar jo. La Clàudia continuava molt bé a Londres i estava aconseguint tot allò que 
havia volgut: li agradava la feina, l'estaven promovent i podia tenir la llibertat que sempre havia desitjat tant econòmica com domèstica. Jo, en canvi, no em veia en cor d'abandonar la meva passió pel periodisme, era molt conscient que era al que em volia dedicar i que hi havia d'invertir molt temps i esforços per poder-ho aconseguir. Havia anat encadenant feineta amb feineta, la majoria feines no qualificades o bé que no estaven relacionades amb els meus estudis; i les que ho estaven eren temporals, precàries o sense remunerar. Portava un temps buit, que sentia que no acabava d'aconseguir allò que volia i amb la Clàudia cada cop eren més discussions. Davant aquella situació vam decidir que el millor era que jo tornés a Catalunya per poder continuar amb els mini projectes periodístics que havia començat estant a Londres: un bloc sobre el procés independentista català i un programa de ràdio una mica diferent, entre d'altres. Ja havia acabat el curs d'anglès, per tant, era professor certificat per donar classes d'anglès a acadèmies i això havia de ser alguna garantia de feina, no? A Londres no em sortia cap feina qualificada ni cap projecte que m’engresqués; en canvi la Clàudia cada cop estava millor a la feina, l'havien pujat de categoria, guanyava encara més diners i estava molt satisfeta amb el que feia, fins i tot va estudiar un màster en finances per poder donar més de si a l'empresa. Per tant, vaig tornar i vam provar això de les relacions a distància, o més ben dit, vam posar a prova la nostra relació a través de la distància.

Un cop a Catalunya no em va ser gens difícil trobar feina de professor d'anglès, vaig trobar diferents empreses que els interessava el meu perfil, tot i que n'hi havia d'altres que no sabien de què anava el certificat que tenia, i això que eren acadèmies d'anglès! El xoc va ser força gran: vaig passar de treballar en acadèmies a Londres que tenien una didàctica molt activa i centraven la seva acció formativa en l'alumne, a un sistema totalment antic a Catalunya on encara s'explicava l'anglès amb la forma clàssica de: subjecte + verb + complements, on tot s'ha de memoritzar i no es té massa en compte l'alumne, només el contingut. El fet d'haver vist el mètode que feien servir a Londres em va permetre fer unes classes molt més actives pels alumnes, cosa que ells també van acabar valorant, i poc a poc em van anar donant més grups i de nivells més avançats; mentre que altres professors que s'havien format a Catalunya (inclús aquells amb el mateix títol que jo), van quedar-se amb grups més petits. Aquestes classes d'anglès em van permetre continuar amb els projectes de periodisme que havia començat, els quals recentment han donat fruit. El bloc sobre el procés independentista ha acabat sent un llibre publicat per una editorial, i el programa de ràdio he guanyat un premi reconegut en el periodisme català. Certament Londres em va permetre posar les llavors a tot el que he anat collint fa poc: tenir una feina mínimament estable com a professor d'anglès, que m'agrada i que em permet sobreviure, i poder-me dedicar a projectes de periodisme que són la meva passió. Crec que la decisió d'haver tornat, encara que signifiqués posar distància física amb la meva parella, que hem aconseguit superar, va ser una bona decisió i m'ha portat a bon port. A Londres no ho estava aconseguint, però sí que vaig poder adquirir coneixements i força per fer-ho a Catalunya, on ara estic començant aquella carrera que sempre he desitjat: el periodisme. El més difícil, però, va ser haver de tornar a viure a casa els meus pares després d'haver-me passat tant de temps vivint en parella.

\section{Anàlisi i conclusions}

Les històries de vida de la Blanca i el Lluís ens han permès acostar-nos al fenomen de l'emigració juvenil catalana a Londres de manera qualitativa. És a partir de les seves vivències que podem entendre alguns elements que caracteritzen el procés d'emigració dels joves catalans en context de crisi. Les dues històries mostren perfils aparentment iguals: joves catalans que marxen a Londres en un context de crisi econòmica; però alhora tenen poc a veure entre ells: la Blanca marxa sola, tenint un mínim de coses preparades (un bitllet d'avió, tres maletes i tres nits reservades a un hostal), amb un nivell d'anglès intermedi i a la recerca d'ella mateixa; mentre que el Lluís marxa amb la seva parella, tenint una beca 
de cinc mesos que li garanteix ingressos, allotjament i feina, amb un nivell alt d'anglès i en busca d'una experiència professional.

Tal i com s'apuntava a la introducció, seria possible aproximar-nos al fenomen a partir d'enquestes, estadístiques i tipologies, però estaríem obviant la riquesa de coneixement que aquesta metodologia ens aporta. Es cert que a partir de les històries d'aquests dos joves no podem generalitzar com són totes les emigracions dels joves catalans, però sí que confirmen els resultats generals de la recerca, obtinguts amb altres mètodes i que la història de vida personalitza (Feixa et alt 2017). El primer d'ells és que tant la Blanca com el Lluís marxen per la falta d'un projecte de futur atractiu a Catalunya, ja sigui perquè la seva feina no els interessa ni els omple professionalment (el cas de la Blanca), com per una impossibilitat de trobar feines relacionades amb els seus estudis i la dificultat de fer la transició a la vida adulta per falta de recursos econòmics (en el cas del Lluís). Per tant, la migració en ambdós casos es relaciona amb una mancança de perspectives, encara que a nivells diferents. Com hem vist, la Blanca ho tenia tot a Catalunya -feina, pis, independència econòmica- $i$ era plenament "adulta" i per tant la seva necessitat estava relacionada amb una plenitud personal i professional; mentre que el Lluís tenia perspectives de fer la transició a la vida adulta amb la seva parella, la Clàudia, a més a més d'assolir una realització professional a partir de trobar una feina com a periodista. Com es mostra en els relats, la Blanca finalment aconsegueix els seus objectius i acaba per trobar una feina relacionada amb la seva professió, la qual també manté un cop retornada a Catalunya; mentrestant que en Lluís aconsegueix independitzar-se amb la seva parella, però no assoleix una feina relacionada amb el periodisme, fet que el porta a retornar. Un cop a Catalunya, però, renuncia d'entrada a la independència domèstica però aconsegueix desenvolupar projectes professionals que li són d'interès.

El segon element que també apunten les històries de vida és la influència dels capitals cultural, social i econòmic previs que ambdós joves tenien abans de marxar a Londres. Tant la Blanca com en Lluís marxen comptant amb un cert capital cultural (ambdós tenen una carrera universitària), econòmic (disposen d'una seguretat d'ingressos per atrevir-se a fer el salt, encara que els estalvis de la Blanca asseguraven un període de temps inferior que la beca del Lluís) i social (tenen una família a Catalunya que els pot ajudar en moments de crisi. En el cas del Lluís fins i tot marxa amb un suport clau: la Clàudia). Aquest capital els dóna eines per afrontar el repte de l'emigració, alhora que també els condiciona les expectatives que tenen a la ciutat d'acollida. Els dos, com hem vist, provenen de classes mitjanes, han invertit molts anys de la seva vida en l'educació i, per tant, esperen poder treballar del que han estudiat. Sí que és cert que a Londres estan disposats a treballar de feines no-qualificades, però aquesta és només una estratègia per integrar-se a la ciutat i posteriorment poder accedir a les feines desitjades. En el cas de la Blanca hem vist que sí que acaba arribant el moment de trobar feina qualificada, així com també ho fa la Clàudia -tot i que ha de fer un canvi de professió- mentre que en Lluís després d'un any i mig a la ciutat no ho aconsegueix i és el que l'acaba fent tornar. Les expectatives laborals, doncs, són un element clau en les seves experiències migratòries, que podrien estar condicionades pel gènere -en aquest cas les dues noies que apareixen a l'article aconsegueixen feines qualificades mentre el noi no ho fa- o bé pel sector professional -en Lluís explica com de tots els periodistes de la seva promoció només la Clàudia aconsegueix una feina qualificada i és perquè fa el canvi de sector.

Un tercer element d'interès és la presència de les noves tecnologies. La Blanca les utilitza per consultar fòrums sobre com preparar l'allotjament els primers dies a Londres i el Lluís per aconseguir una empresa on poder fer la seva estada de la beca Leonardo da Vinci. D'alguna manera l'internet i les tecnologies de la comunicació han acostat la realitat londinenca als dos joves, fent-la més propera i accessible, a més a més dels vols low-cost que han facilitat els desplaçaments entre ciutats europees. Aquest element obre una pregunta per a futures recerques: haurien marxat si no haguessin existit les noves tecnologies? S'ha- 
guessin atrevit a marxar sense conèixer tot el que coneixien i, més important, sense poder mantenir el contacte amb la gent de Catalunya? Certament les noves tecnologies han fet la seva experiència més fàcil, els han permès conèixer la ciutat però alhora també accedir-hi sense haver de comprar-se el diari cada dia i encerclar les ofertes de pis i de feina com es feia abans. Les noves tecnologies, doncs, han estat clau en les experiències dels dos joves, fent que el seu procés fos més accessible, així com per relacionar-se amb la família i amics a Catalunya i amb la resta d'immigrants catalans a Londres.

Finalment, un altre element que es desprèn de les històries de vida és la necessitat dels dos joves de provar-se a ells mateixos, és a dir, de posar-se reptes i d'assolir-los. Tant la Blanca com el Lluís estan buscant un creixement personal, que vinculen també a un creixement professional. Londres per a ells és una etapa d'autoconeixement, de veure fins on són capaços d'arribar. En el cas de la Blanca és molt evident, decideix marxar sense res per veure quant de lluny pot arribar; però en el cas del Lluís també hi és present, posant-se la pressió contínua de trobar projectes periodístics als que dedicar-se, provant que és capaç d'aconseguir-ho. Londres, per tant, és una prova, un examen a nivell personal al que han decidit sotmetre's per veure fins on són capaços d'arribar. La Blanca obté els resultats de manera immediata: aconsegueix passar de tenir tres nits d'hostal i tres maletes a una casa, una feina qualificada i uns ingressos suficients com per viure bé a una de les ciutats més cares del món. El Lluís aconsegueix el seu objectiu però ho fa de manera més tardana, un cop és a Catalunya. I és que la seva professió és una mica diferent, l'etapa de Londres li serveix per plantar llavors, de les quals en veu els fruits dos anys després: un llibre i un premi per un programa de ràdio. Tot $\mathrm{i}$ que ell ho relaciona amb la seva estada a Londres, no podem assegurar, però, que aquests fruits hagin estat gràcies a ella.

Aquesta necessitat de provar-se a un mateix, de conèixer que hom pot aconseguir el que es proposa, va molt lligada a una idea ancorada en l'imaginari col·lectiu sobre els processos migratoris anomenada "el camí de l'heroi", la qual prové dels mites greco-romans on els herois són sotmesos a grans proves per demostrar la seva valentia i vàlua a nivell social. Es tracta de persones cridades pels déus a passar proves que requereixen perícia física i intellectual, que després d'una llarga i àrdua aventura aconsegueixen sobrepassar, tot retornant a la seva societat d'origen convertits en herois. Londres, d'alguna manera, seria aquesta aventura que els joves escollits han de passar: han d'atrevir-se a anar-hi, superar les proves (trobar allotjament, feina, una xarxa social, etc) perquè, un cop superades, puguin retornar a Catalunya com a persones més fortes i valentes i se'ls pugui reconèixer l'esforç. No obstant, com es mostra a les històries de vida, aquestes proves incorporen moments molt durs per a ells, els quals no es responen a les expectatives que tenien de l'experiència londinenca ja que no eren conscients de la cara oculta del procés migratori abans de marxar. Moments durs que, en el cas de la Blanca, fan que els joves experimentin en la seva pell l'estigma de ser immigrant (Rubio et alt, 2017).

Malgrat ells mateixos no considerin de manera conscient aquest "camí de l'heroi" com a una explicació al seu procés migratori, sí que declaren que la seva experiència a Londres els suposarà un mèrit especial quan retornin a Catalunya, distingint-los de la resta de joves que busquen feina i no han tingut cap experiència a l'exterior (Rubio i Strecker 2017). Paral·lelament, l'explicació del "camí de l'heroi” dóna resposta també una de les preguntes àmpliament debatudes en el cas de l'emigració dels joves catalans: com pot ser que els joves es disposin a deixar el benestar de casa seva per marxar a un altre país a treballar de feines no qualificades i sovint precàries, tenint l'opció de fer el mateix al seu país de manera més fàcil? Com pot ser que un jove renunciï a treballar a cadenes de menjar ràpid a Catalunya però ho faci sense protestar a Londres? Com s'ha vist en el cas de la Blanca i el Lluís aquestes feines no-qualificades es concebrien com a una primera prova a superar amb la intenció d'assolir el vertader objectiu pel qual han marxat: tenir una feina qualificada que tingui el segell internacional. Per tant, entendrien aquestes feines no-qualificades com el primer pas 
que han de fer per tal d'integrar-se a la societat (conèixer com funciona el sistema laboral, aprendre l'idioma, etc) i així aconseguir una feina qualificada que els permeti enriquir el seu currículum.

Finalment cal dir que l'exercici d'escriure aquests relats en forma d'història de vida m'ha portat a revisar les dades recollides anant més enllà de l'anàlisi a partir de categories i buscant les significacions que donen al fenomen els propis informants. Aquest exercici de comprensió profunda de les històries de vida és clau per tal de poder aportar informació en profunditat i una anàlisi intersubjectiva, tot buscant entendre (i plasmar en el paper) de quina manera els informants viuen aquestes experiències.

\section{Bibliografia}

Bakhtin, Mikhail (1994 [1981]). The Dialogical Imagination. Austin: University of Texas Press.

Cabré, Anna; Domingo, Andreu (2013). "La emigración desde Cataluña: aspectos demográficos y prospectivos. Dins: Sánchez, Elena; Alonso, Xavier (eds). Nuevos flujos y gran recesión. Barcelona: Cibob.

Feixa, Carles (2006). "La imaginación autobiogràfica". Perifèria, 5

Feixa, Carles; Rubio, Clara; Ganau, Joan; Solsona, Francesc (eds) (2017). L'emigrant 2.0. Emigració juvenil, nous moviments socials $i$ xarxes digitals. Barcelona: Estudis.

Ferrarotti, Franco (1974). Vite di baraccati. Nàpols: Liguori

Ferrarotti, Franco (1981). Storia e storie di vita. Bari: Laterza

Kluckhohn, Clyde (1945) "The Personal Document in Anthropological Science”. Dins: Louis R. Gottschalk et alt. The use of Personal Documents in History, Anthropology and Sociology. Nova York: Social Science Research Council

Mills, Charles (1977 [1959]) La imaginación sociològica. Mexico: FCE

Niethammer, Lutz (1989). "Para qué sirve la Historia Oral?". Historia y Fuente oral, 2, 3-25.

Pujadas, Juan José (2002). El método biográfico: el uso de las historias de vida en ciencias sociales. Madrid: Cuadernos Metodológicos CIS

Rubio, Clara; Clua, Montserrat; Sánchez, José (2017) "La identita migrant dels joves catalans a Londres” En C. Feixa; C. Rubio; J. Ganau; F. Solsona (eds), L'emigrant 2.0. Emigració juvenil, nous moviments socials i xarxes digitals (pp-153-170) Barcelona: Estudis.

Rubio, Clara; Strecker, Tanja (2017) “Aquí i allà: els plans d'emigració de les persones joves universitàries i les realitats que troben a Londres" En C. Feixa; C. Rubio; J. Ganau; F. Solsona (eds), L'emigrant 2.0. Emigració juvenil, nous moviments socials i xarxes digitals (pp153-170) Barcelona: Estudis.

Thomas, William I.; Znaniecki, Florian (1958 [1918-1920]) The Polish Peasant in Europe and America. Nova York: Dover Pub.

\section{$\operatorname{cocos}$}

